\title{
TERRITORIO, MIGRACIÓN E IDENTIDAD ÉTNICA MAPUCHE EN CHILE.
}

\section{TERRITORY, MIGRATION AND ETHNIC IDENTITY MAPUCHE IN CHILE}

\section{AUTOR}

\section{Carlos del Valle Rojas}

Departamento de Lenguas, Literatura y Comunicación Universidad de La Frontera (Chile) delvalle@ufro.cl

\section{RESUMEN}

El presente trabajo aborda el fenómeno de la migración de las comunidades indígenasmapuches desde la periferia rural a los centros urbanos en Chile, con la perspectiva de la interculturalidad como hecho de comunicación inmerso en un sistema de relaciones de diferencia, de poder y control social. Lo anterior exige una re- lectura de las relaciones interculturales, para lo cual se tomará el ejemplo de la relación de los indígenas mapuches de Chile con el sistema judicial, el cual durante los últimos cuatro años ha transitado desde el control y la violencia a través de la escritura, hacia la reducción e instrumentalización de la oralidad como forma de economía procedimiental. 


\section{PALABRAS CLAVE}

Territorio- Migración - Identidad

\section{ABSTRACT}

This paper addresses the phenomenon of migration of the indigenous communitiesmapuches from rural periphery to the urban centers in Chile, with the prospect of interculturality as fact communication immersed in a system of relations of difference, power and social control. This requires a re-reading of intercultural relations, which will take the example of the relationship of the mapuche indigenous of Chile with the judicial system, which during the past four years has gone from the control and violence through the scripture, toward the reduction and instrumentalisation of orality as a form of procedural economy.

\section{KEY WORDS}

Territory - Migration - Identity

\section{ÍNDICE}

1. Aproximaciones teórico - conceptuales

Cultura y oralidad.

2. Desarrollo

2.1. La cultura como sistema de relaciones de diferencia

2.2. Comunicación, conflicto y diferencia

2.3. El conflicto y la ley como fundamento

2.4. Re- pensando las fronteras

2.5. Control, violencia y racismo desde / a través de la escritura

2.5.1. El orden público 
2.5.2. El Estado-nación como proceso y producto discursivo en la escritura

2.5.3. Los partes policiales como huella y como relato socialmente legitimado.

\subsection{La historia escrita}

3. consideraciones finales

"[el] fracaso final de la sociedad en su intento de constituirse a si misma como sociedad [o] el fracaso de la constitución de la diferencia como diferencia [es] lo que torna insuperable la distancia entre lo universal y lo particular $y$, en consecuencia, impone a los agentes sociales concretos esa tarea imposible que hace posible la interacción democrática" (LACLAU, Ernesto, 2000: 267 y 268)

\section{Aproximaciones teórico-conceptuales}

El concepto fundamental es el de espacio, el cual se define como el sistema de relaciones de diferencia de las comunidades que se inter- relacionan y, al mismo tiempo, como un complejo social, cultural, económico, político y legal. No obstante, en este trabajo, nos centraremos más en los aspectos culturales, en general, y los aspectos legales (sistema "jurídico-judicial"), en particular, como espacios relacionales ${ }^{1}$. En este caso específico, observamos que la cultura indígena pasa de la discriminación por

\footnotetext{
${ }^{1}$ De hecho, el material utilizado como referencia permanente en el presente artículo, corresponde específicamente a: (a) un proceso judicial basado en una querella contra un grupo de indígenas mapuches en Chile, como presuntos autores de un atentado incendiario contra una empresa forestal (diciembre de 1997 a abril de 1999); (b) casos del nuevo sistema procesal penal en Chile, a partir de diciembre de 2000, y su relación con las comunidades indígenas mapuches $\left({ }^{\mathbf{1}}\right)$. Y, por último, los ritos mapuches como expresión de la construcción simbólica de los sujetos-y/en-la-comunidad
} 
REVISTA DE LA SEECI.

Del Valle Rojas, Carlos (2004): Territorio, migración e identidad étnica mapuche en Chile. No11. Noviembre. Año VIII. Páginas: 107-129

ISSN: 1576-3420 DOI: http://dx.doi.org/10.15198/seeci.2004.11.107-129

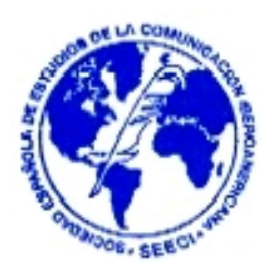

invisibilización y silenciamiento (la inexistencia constitucional como pueblo y la imposición de un sistema, en el caso del actual, desde principios del siglo XX) a una forma de discriminación por desconocimiento y reducción simbólica y cultural (la oralidad es confinada a un hecho tecnológico del lenguaje y sometido a una racionalización instrumental que no la incorpora como productora de sentido; sino como un instrumento que permite reducir los procedimientos del aparato burocrático judicial).

\subsection{Cultura y oralidad}

La oralidad $\left({ }^{2}\right)$ emerge con especial fuerza los últimos años, como diferencia producto de los conflictos entre indígenas y no-indígenas. En este trabajo, abordamos la oralidad: (a) como hecho cultural de diferenciación que surge tras la Inter- acción de las comunidades en el espacio, producto de la migración; y (b) como instrumento que permite la reducción de los procedimientos del aparato burocrático judicial.

La oralidad como producción textual compleja - y no como mera tecnología del lenguaje e instrumento de racionalidad procedimental-, emerge como instancia de producción de sentido caracterizada por:

(a) La memoria, pues el uso del lenguaje está directamente relacionado con la capacidad de registro y conservación de la información. Y en la práctica, también se observa en la forma cómo los sujetos mapuches construyen los relatos: invocando recursos del pasado en la construcción de las historias (actores, roles y conflictos en los cuales predomina la relación bien/mal) y empleando de forma particular el tiempo.

\footnotetext{
2 Para profundizar sobre la oralidad, ver los trabajos de: KAISER (1961); LABOV (1972); CREES (1979); CHAFE (1980); ONG (1987); HALLIDAY (1989); BROWN y YULE (1993); CARDONA (1994); MARCONE (1997); BLANCHE-BENVENISTE (1998) y MARIACA, BLONDET y CASALMIGLIA y TUSÓN (1999).
} 


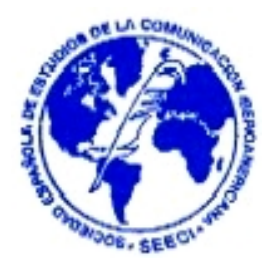

(b) La repetición, como forma de conservación de la información, a través de la memoria. La repetición como forma de nutrir la memoria para la producción oral es un aspecto siempre presente en las prácticas conversacionales de los sujetos mapuches.

(c) El uso de ciertas fórmulas ligadas a formas poéticas. La producción de la oralidad requiere ciertos recursos de lenguaje que operan como mecanismos mnemotécnicos para el hablante. Por lo tanto, en las construcciones orales se puede advertir estas fórmulas.

(d) El uso de ciertos ritmos, ligados a cierta métrica poética y que constituyen el modo cómo se produce la oralidad en las conversaciones. Nos referimos aquí a la musicalidad que tiene el hablante mapuche y el uso de ciertos ritmos. Estos dos aspectos (musicalidad y uso de ciertos tiempos) es fundamental para comprender las interacciones de los sujetos mapuches. En efecto, los actuales estudios de la oralidad indígena se abordan desde teorías musicales y no sólo desde teorías lingüísticas, textuales o semióticas, como se ha venido haciendo (PAINEQUEO, 1994).

(e) La tematización. En las conversaciones de sujetos indígenas, el abordaje temático es más lento y riguroso que en sujetos no-mapuches.

No obstante, la oralidad ha sido socializada e integrada a la "cultura global" mediante procesos de control cultural. Las actuales "medidas interculturales" - no políticas sistemáticas-, reducen la cultura a sus aspectos idiomáticos y la oralidad a sus aspectos materiales e instrumentales, re- introduciendo las estructuras idiomáticas entre los indígenas conforme al modelo mayoritario, es decir, alfabetizando la lengua y llevándola a la escritura. Como resultado, coexisten más de cinco alfabetos - entre los oficiales del Estado, los de estudiosos de la lengua y los de reivindicación indígena. Sin embargo, hablar de una cultura oral es más que hablar de una cultura que prescinde de la escritura - lectura, por cierto, realizada desde la escritura: la oralidad es, pues, una forma particular de ver, producir, re- producir, comunicar y representar el mundo. No cambia sólo el código idiomático, sino también todo el complejo entramado de códigos culturales, sociales, religiosos, etc. En efecto, la oralidad aparece con especial fuerza en 
REVISTA DE LA SEECI.

Del Valle Rojas, Carlos (2004): Territorio, migración e identidad étnica mapuche en Chile. No11. Noviembre. Año VIII. Páginas: 107-129

ISSN: 1576-3420 DOI: http://dx.doi.org/10.15198/seeci.2004.11.107-129

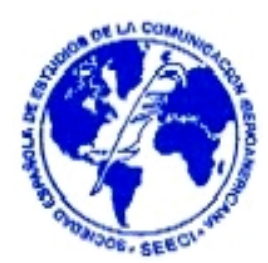

condiciones conflictivas, asomando como una diferencia-en-contexto, y no como un mero "rasgo cultural". La oralidad es y hace, es una forma de actuación de la cultura frente al entorno y como tal, está en permanente dinamización que va entre lo material (lingüístico) y lo simbólico (contra- poder, inter-textualidad y resistencia).

\section{Desarrollo}

\subsection{La cultura como sistema de relaciones de diferencia}

En este escenario de "migración intra- regional" ${ }^{3}$ de las zonas rurales hacia las zonas urbanas, se generan conflictos por la serie de demandas y reivindicaciones indígenas, las cuales, a su vez, producen las diferencias entre las comunidades que actualmente habitan las zonas urbanas y estos "inmigrantes" de las zonas rurales.

Debemos entender la diferencia en nuestras sociedades como diferencias-en-contexto y no como diferencias aisladas o meras reacciones de resistencia puntual:

"No puedo afirmar una identidad diferencial sin distinguirla de un contexto $y$, en el proceso de hacer esta distinción, estoy afirmando el contexto [y asimismo] no puedo destruir un contexto sin destruir al mismo tiempo la identidad del sujeto particular que lleva a cabo la destrucción". (LACLAU, 2000:260)

\footnotetext{
${ }^{3}$ Se emplea este concepto para señalar el proceso migratorio de las comunidades locales, en este caso indígenas mapuches, desde las zonas periféricas rurales hacia las zonas céntricas urbanas; fenómeno que se observa normalmente dentro de la misma región, siendo la capital regional el sector de destino: "migración intra- regional"; o bien, hacia otras regiones, siendo la capital del país el destino principal: "migración inter- regional". Soy consciente de la limitación de esta conceptualización, toda vez que nos restringen a la noción de frontera espacial en la dinámica de comunicación intercultural. No obstante esta ambigüedad semántica, empleo estos conceptos en lugar de otros como el de intra- migración, por su mayor ambigüedad.
} 


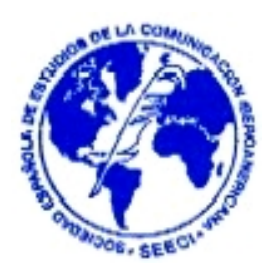

En este sentido, las diferencias de la particularidad "indígena-mapuche" en la migración rural-urbano, reafirman el contexto en que ocurre dicha migración: la ciudad como espacio-conflicto. La ciudad y lo urbano, también, como un nuevo campo de interlocución; esto es, como un espacio nuevo de relaciones y de re-configuración de "unos" y "otros". Y, como insiste LACLAU, en este espacio, contexto o campo, se confunden lo particular y lo universal, lo local y lo global:

"La separación -o, mejor dicho, el derecho a la diferencia- tiene que ser afirmado dentro de una comunidad global, esto es, en un espacio donde el grupo particular tiene que coexistir con otros grupos".(LACLAU, 2000:265)

\subsection{Comunicación, conflicto y diferencia}

Como lo explicábamos más arriba, el conflicto se vincula a la migración de las comunidades indígenas mapuches hacia nuevos espacios específicos; y a partir de dicho conflicto surgen las diferencias, como es el caso de la oralidad, en el marco del control y la violencia a través de la escritura; y de los ritos, en el marco de la re- producción económica de la cultura. Aunque, en ambos casos, claro está, nos referimos a fenómenos anteriores a las interacciones culturales, que se re- construyen en el conflicto como diferencias-en-contexto.

La inter- culturalidad y la comunicación intercultural constituyen en la actualidad discursos muy frecuentes, particularmente ante la preocupación por los fenómenos de migración, en Europa, y los fenómenos de reivindicación indígena, en Latinoamérica. No obstante, para hablar con mayor consistencia de interculturalidad y comunicación intercultural, se requiere, al menos, las siguientes consideraciones: 
a. Comprender el conflicto y la diferencia como factores fundantes de nuestro sistema de relaciones y no como obstáculo para dichas relaciones. El conflicto es, pues, base del desarrollo y dinámica cultural, particularmente en comunidades indígenas. Es a través del conflicto que estas comunidades han enfrentado los espacios emergentes e impuestos de convivencia: la globalización religiosa de la colonización, la globalización de los Estadosnación y la actual globalización del mercado $\left({ }^{4}\right)$; y desde estos conflictos surgen las diferencias. La dinámica del conflicto y las diferencias podemos entenderla también en la relación universal-particular, global/local, en el sentido que plantea LACLAU:

"esta paradoja no puede resolverse, pero su no-resolución es la pre-condición misma de la democracia. La solución de la paradoja implicaría que un cuerpo particular habría sido encontrado, que sería el cuerpo verdadero de lo universal. Pero en este caso lo universal habría encontrado su emplazamiento necesario y la democracia sería imposible". (LACLAU, 2000: 267 Y 268)

Siguiendo a LACLAU -o separándonos de él, dependiendo de los alcances de lo no-dicho en lo que plantea-, el conflicto pasa a ser un factor fundamental de la inter- culturalidad en la medida que las relaciones entre culturas devienen universal y particular, el conflicto-entre-lo-universal-y-lo-particular, la lucha entre la cultura de "unos" minorizada, no siempre minoritaria, y la

\footnotetext{
4 Sobre la evolución de las formas de globalización, ver MORENO, I. (2002): "religión, Estado y mercado. Los sacros de nuestro tiempo", en ZAMBRANO, C. (Ed.): Confesionalidad y política. Confrontaciones multiculturales por el monopolio religioso, pp. 35-52, Bogotá, Universidad Nacional de Colombia.
} 
cultura de "otros" mayorizada, no siempre pero "suficientemente" mayoritaria. Es este conflicto, como "entre", lo que sustenta y hace posible la interacción, la interculturalidad, el multiculturalismo y la democracia. Por ello, no es posible apoyar el discurso de la clase política chilena cuando plantea que una solución al "conflicto indígena" es reclamar la aplicación rigurosa del "Estado de derecho"; lo cual supone imponer las particularidades del Estado, transformándolas en un universal, como la noción de orden público aplicada a los litigios territoriales entre indígenas y empresas privadas. De la aplicación de un "Estado de derecho" al "terrorismo de Estado" los límites, si existen, son muy sutiles.

b. Re- discutir los grandes discursos, como: Estado- nación, derechos universales, Estado de derecho, unidad nacional, fronteras, políticas de integración, entre otros.

c. Re- pensar el espacio-conflicto, geográfico, cultural y simbólico y la economía política y el sistema judicial que lo configuran.

\subsection{El conflicto y la ley como fundamento}

El conflicto entre las familias indígenas mapuches y las empresas transnacionales de explotación maderera y eléctricas en Chile se materializan en frecuentes y cada vez más violentos conflictos en los espacios de inter- acción. El Estado actúa en una sola dirección: aplicación de la Ley de Seguridad Interior y de la Ley Antiterrorista para los indígenas; y/o bien, compra los terrenos a las empresas a altísimos costos y los entrega a las comunidades indígenas. Su dinámica es así reactiva y como propuesta asume un doble rol: paternalista, subvencionando a través de las compras de terrenos; y represiva, castigando duramente. Las comunidades sufren así un "doble vínculo". 


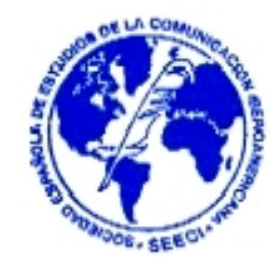

En este contexto, lo legal se ha planteado históricamente como un elemento de "resolución de los conflictos":

(a) Las Leyes de Constitución de la Propiedad Austral (10 de Junio de 1823), títulos que el Estado chileno entregó a los indígenas mapuches que habitan al sur del país (Huilliches).

(b) Los títulos de Merced, títulos comunitarios extendidos a favor de los denominados primeros radicados: indígenas que reclamaron determinadas porciones de terreno en el período posterior a la ocupación militar de La Araucanía y hasta las primeras dos décadas del siglo XX.

(c) En 1860 se crean las Leyes de Reducciones Indígenas y hasta 1920 este proceso forma más de tres mil reducciones; siendo la comunidad reduccional un espacio de reproducción cultural, reafirmación de identidad e intercambio de los principales bienes. Esta combinación de autosubsistencia y cultura de resistencia es lo que otorga a la sociedad mapuche post reduccional un equilibrio que impide que procesos de desestructuración y desintegración violentos se produzcan en su interior (AYLWIN, J., 1999:27).

(d) Entre las leyes dictadas posteriormente, para dividir los títulos comunitarios y transformarlos en propiedades individuales, están: Ley № 169 de 1927, Ley № 4 802 de 1930, Decreto Supremo № 4.111 de 1931; Ley № $14 . .511$ de 1961, y Ley № 17.729 de 1972 y sus modificaciones. A estas hay que agregar la Ley № 17.729 de 1972, Decreto Ley № 2.568 y 2.750 de 1979; Decreto Ley 2.695 de 1979, Decreto Ley 3.516 de 1980, Ley Orgánica del Servicio Agrícola y Ganadero SAG y Código Civil. 


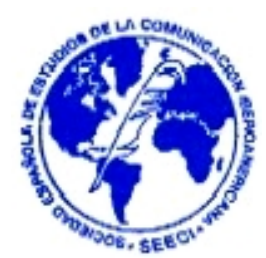

Uno de los principales conceptos de la Ley Indígena (Ley № 19.253 de 1993), y el más cuestionado en la actualidad, es el concepto de "protección de los pueblos indígenas", pues los mapuches expresan que no se sienten protegidos, sino vulnerables frente a la ley y la aplicación de justicia. En la práctica, los mapuches deben interactuar con un sistema que no hace ninguna distinción socio-cultural, pues se les sigue identificando como grupos pobres, para acceder al beneficio de políticas sociales, sin que se establezcan distinciones de etnia (DAVINSON, 2000:37). Lo mismo ocurre en el acceso directo a la justicia, pues no se incluye la variable cultural al momento de realizar los juicios. $\quad Y$ en el caso del actual sistema, sólo existe la posibilidad de incorporar la variable cultural a través de los traductores y jurídicamente mediante atenuantes, eximentes, salidas alternativas y postergación de juicios. En este sentido, ellos siguen percibiendo la justicia como discriminación (DEL VALLE, C., 2001b:125).

No obstante, los mapuches en su histórica relación con la sociedad mayoritaria y mayorizada, han asumido el conflicto como factor de "desarrollo cultural" y no como "obstáculo del progreso o del desarrollo", según la lectura del discurso público del gobierno, del mercado y de los medios. El conflicto no se limita al enfrentamiento y la relación que establece con lo policial o lo penal, sino también es un factor que históricamente ha permitido su conservación como cultura. Este aspecto ha sido muy poco tratado como tal, puesto que a través del discurso público y mediático se ha estigmatizado a los indígenas mapuches como "conflictivos" en una acepción absolutamente negativa.; $y$, por ello, como un problema permanente para el desarrollo. No obstante, es el conflicto el productor permanente de las diferencias y éstas configuran las "identidades de resistencia", donde la oralidad opera como contrapoder e intertextualidad. 


\subsection{Re- pensando las fronteras}

La noción de fronteras no se reduce a lo geográfico, sino que se extiende a lo cultural y simbólico. Por esta razón, hablamos de espacio-conflicto, geográfico, cultural y simbólico.

"Las fronteras no son espaciales, sino entre distinciones colectivas de grupos sociales y la distribución de 'rasgos culturales' [...] las fronteras son situacionales y no primordiales". (BARTH, 1976)

La frontera es un discurso y un imaginario productor de sentido y, en este mismo sentido, no es un lugar, sino un no-lugar codificado permanentemente como espaciode-conflicto, presente en todas partes.

Y como referencia a un espacio-de-conflicto, lo que tradicionalmente conocemos como

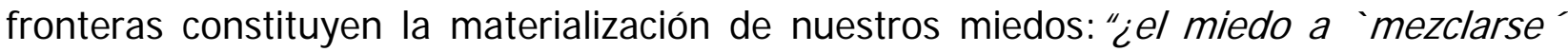
hará que surjan nuevos límites y obstáculos a [la] lógica aparentemente incluyente?". (BARCELLONA, 2000:114)

En síntesis, entendemos aquí las fronteras como discurso e imaginario que da sentido a los espacios-conflicto que, en realidad, son un no-lugar, un descentramiento de la pertenencia in situ. Siguiendo a WEIL (1997), CAPELLA (2000) desarrolla el concepto de "raíces culturales comunitarias", para referirse a ciertos elementos culturales básicos que nos permiten socializar e individualizar, como la lengua, las creencias, tradiciones, etc. (CAPELLA, 2000: 74). Coincidiendo en general con esta idea de elementos culturales básicos -especialmente como descripción y análisis, a la manera de los "rasgos culturales" de BARTH (1976)- y en la dinámica socializadora de ésta, que nos permite aprender a reconocer hechos de cultura más o menos ajenos (CAPELLA, 


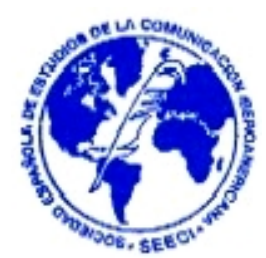

2000:74); me preocupa la falta de flexibilidad a la que nos puede llevar esta idea, en el sentido de que estas "raíces culturales comunitarias" refieren elementos culturales que, pudiendo ser propios o no, básicos o no, emergen y se re- producen en el espacioconflicto donde ocurren las interacciones entre culturas. En efecto, por ejemplo la lengua de una comunidad indígena mapuche -cuyos hablantes no son monolingües de dicha lengua, sino bilingües (se estima en no más de un $1 \%$ el monolingüismo del mapuzungün o lengua mapuche en Chile)-, emerge como elemento cultural básico en la medida que surge como diferencia en el espacio-conflicto. No antes. Está allí, es verdad. Pero emerge cuando una comunidad desea cerrar la interacción -como lo hacen los afroamericanos con los hispanos en Estados Unidos- como resultado del conflicto. De lo contrario no emerge: los hablantes indígenas lo son de ambas lenguas, es más, principalmente del español: una será la que permite la interacción (español) y otra la que la cierra (mapuzungün). Entonces, dichos elementos culturales básicos son, en realidad, parte de una dinámica relacional conflictiva. Por ello, resultará más útil la noción de rizoma, en la medida que tiene sentido con el no-lugar, el no-otro y no-yo, un "entre". Y en dicho espacio-"entre" no acaba el conflicto, sino que se re- produce ad infinitum - la semiósis ilimitada preconizada por PEIRCE Y ECO- en la interacción.

\subsection{Control, violencia y racismo desde/a través de la escritura}

A continuación, veamos algunas categorías que surgen del sistema de relaciones entre comunidades mapuches y no mapuches, Estado, escritura y ley; tomando como ejemplo el análisis del caso de un grupo de sujetos mapuches sometidos a un proceso penal por su presunta responsabilidad en un atentado contra una empresa privada (DEL VALLE, 1998,2000 y 2001): 


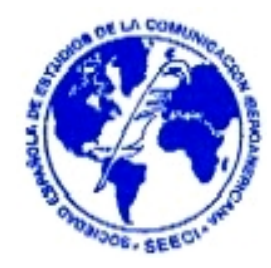

\subsubsection{El orden público}

Surge como una noción de importancia en los procesos, no sólo por su carácter jurídicojudicial, sino por su carácter estratégico; toda vez que traslada los intereses desde un ámbito particular (propietarios de los predios vs. mapuches que los reclaman) a un ámbito social mayor, que compromete los intereses de la sociedad (orden público). Dicho desplazamiento, como es obvio, no es casual y da cuenta de la manera cómo una de las partes entiende el accionar de la otra. Independientemente de la gravedad o no de los hechos y de la culpabilidad o no de determinados sujetos, la noción de orden público (y su contraparte jurídico-judicial, la Ley de Seguridad del Estado y la Ley Antiterrorista), constituye un modo particular no sólo de entender la acción de los sujetos, sino la interpretación de suS actuaciones en la sociedad y la cultura. Como otras nociones "fetiche" utilizadas para contener la lógica del poder del estado es tan efectiva como ambigua: ¿qué es el orden público?, ¿quién lo determina?, ¿quién determina sus límites?; ¿cuántos juicios en que se sanciona a los indígenas se justifican en apelaciones a esta noción?.

Asimismo, observemos la noción gramatológica que subyace en el orden público, pues este orden público existe sólo en la medida de su escritura en un ordenamiento jurídico determinado.

2.5.2. El Estado-nación como proceso y producto discursivo en la escritura.

Esta unidad político-social llamada Estado-nación funciona como eje articulador de ciertas acciones. Será el Estado el responsable de velar por el orden público. Y el estado, como hecho de poder burocratizado, tiene sentido a partir del discurso que lo genera, apoyado por su registro, su escritura, donde: "No hay lugar para los indígenas ni para los negros en el relato oficial de [el Estado-] la nación". (GRIMSON, 2000:49) 


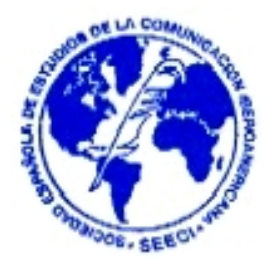

2.5.3. Los partes policiales como huella y como relato socialmente legitimado.

La relevancia que adquieren los partes policiales en la producción de estos discursos nos exige centrar también nuestra atención en ellos. Su incorporación en la rutina productiva de los tribunales y del proceso en general, permite entender la fuerte presencia de ciertos relatos factuales en el proceso. En lo ocurrido el 10 de diciembre de 1997, cuando presuntamente el grupo de mapuches incendia tres camiones de una empresa forestal, constituye a partir de los partes policiales como huella, como escritura $\left({ }^{5}\right)$, una construcción casi mítica en el proceso, indesmentible e indiscutible hasta la sentencia (condenatoria).

\subsection{La historia escrita.}

En la lógica de relación entre poder legal centralizado - comunidades indígenas, se apela a la historia (y el cuerpo de leyes que demarcan esa historia y sus protagonistas: vencedores/ vencidos, civilizadores / civilizados), pero a una cierta historia escrita y legitimada por los "vencedores" y "civilizadores". Desde el poder no hay posibilidad para legitimar otras historias como las que proceden de la cultura oral de los vencidos y civilizados.

\section{Consideraciones finales}

1. Entender los procesos judiciales con componentes étnicos, y de paso entender estos procesos judiciales como procesos de producción discursiva, permite una nueva aproximación a este ámbito. Ello nos obliga a entender lo jurídico-judicial

\footnotetext{
5 Sobre las nociones de huella y escritura, me refiero fundamentalmente a los trabajos de DERRIDA, Jacques (1971, 1988 y 1989). [Todas corresponden a ediciones posteriores en español].
} 
como una construcción social, enmarcada en una red de discursividades legales; donde, naturalmente, operan mecanismos de poder y control social y de decisiones desde el ámbito del poder del discurso (sometimiento de la verdad de los "otros" a la verdad de "no[s]otros", donde "otros" y "nosotros" están jerarquizados a priori en el discurso y las prácticas. Es relevante, entonces, discutir cómo se producen, quién produce y para qué producen ciertos discursos en nuestra sociedad, para salir de la racionalidad que obliga a establecer la verdad y la justicia. Así, no sólo cabe la necesidad de re- discutir la o las juridicidad(es), sino de re- pensar los mecanismos de exclusión y dominación actualmente subyacentes: las "verdades jurídicas", las "razones de Estado", el "Estado de derecho" y las "prácticas judiciales". Y cómo podemos re- producir estos discursos desde una relación horizontal entre culturas y no desde la integración o dominación cultural. Obviamente, esto supone fuertes transformaciones a la cultura jurídica. Podemos observar cómo operan mecanismos y dispositivos de control social: como el uso de ciertas discursividades específicas (por ejemplo, el lenguaje jurídico y las rutinas de los tribunales). Así, ya no enfrentamos la búsqueda de la verdad, sino más bien el sometimiento de la verdad de "nos(o)tros" sobre "otros": ¿de qué manera la pretensión de verdad de "unos" se ve respaldada por la ley y la institucionalidad y la de "otros" queda excluida?

2. La oralidad como producción simbólica y cultural. En este sentido, entendemos que la oralidad también es una tecnología que "cree en la memoria comunal y la significación como proceso testimonial y representacional [donde] la experiencia, la subjetividad y la afectividad son fundamentales" (MARIACA, 1999:26).

3. Las reivindicaciones. La identidad reivindicativa frente a la diferencia como discriminación. Si observamos los procesos en que las comunidades indígenas 


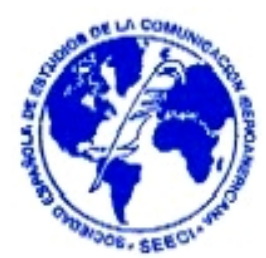

mapuches plantean sus demandas y reivindicaciones, en el contexto de la construcción de una identidad, resulta importante advertir, en el ámbito del discurso jurídico, cómo se construye una relación bélica, a partir de la reconstrucción de la historia. Esta identidad también se relaciona con elementos supra- nacionales, pues se invoca en la construcción discursiva los parlamentos históricos y las leyes internacionales. Asimismo, la búsqueda de indemnizaciones, propia del discurso jurídico, es parte de esta identidad reivindicativa. Y si bien se apela al sistema judicial chileno, en lo jurídico se restringe la actuación de los instrumentos judiciales del estado (por razones también históricas, se margina los tribunales al sur del Bío-Bío). Por su parte, el uso de este discurso jurídico supone la incorporación de un nuevo lenguaje, en el cual las acciones extra- judiciales como la toma de tierras adquieren una nueva configuración: quienes efectúan las tomas de tierras, en lo sucesivo dirán que son actos en legítima defensa.

Finalmente, debemos consignar que en las representaciones sociales de los líderes y dirigentes mapuches sobre el sistema judicial, éste es un mecanismo de control y dominación; y el nuevo sistema procesal penal es concebido sólo como una forma más sofisticada de llevar a cabo dicho control y dominación.

Estos elementos discursivos están presentes también en otros tipos discursivos más públicos y cotidianos. Será un desafío descubrir la manera de avanzar en la relación pueblo Mapuche - Estado de Chile, a partir de estos antecedentes.

4. Para lograr un verdadero cambio cultural, en el ejercicio de la justicia, se requiere cambiar ciertas estructuras cognitivas e institucionales que vulneran principios vitales de la justicia, como la no discriminación. Desde el año 1995 a la fecha, período que comprende seis años de sistema tradicional y dos años de reforma al 


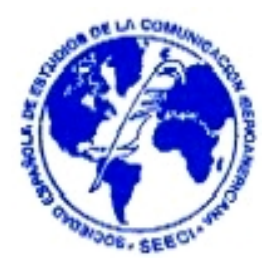

sistema en la IX Región de Chile, el Estado- nación ha jugado un rol fundamentalmente atentatorio al espíritu de la justicia.

5. El problema de la accesibilidad al sistema, especialmente de los indígenas mapuches, es fundamental. Y no basta con la incorporación de traductores, sino que requiere cambios profundos en la manera de enfocar la relación entre el nuevo sistema y sus actores: (a) un estado y un aparato estatal menos centrado en la diferencia como instrumento de discriminación, pues entender al otro es más complejo que discriminarlo; (b) un sistema jurídico- judicial y estatal que acepte las diferencias como parte de su complejidad y permita asumir dichas diferencias: ¿generando tribunales indígenas mapuches para la resolución de cierto tipo de conflictos penales y civiles?, ¿incorporando el bilingüismo sin censura?; en definitiva, asumiendo la inter- culturalidad como parte integrante del sistema y no como una excepción de él. En efecto, como se ha planteado, la convivencia entre culturas, como hecho comunicativo, se sitúa en un sistema de relaciones de diferencia, de poder y control; en cuyo caso la diferencia es producto y no productora del conflicto (GRIMSON, 2000:34).

6. La identidad como resistencia y la oralidad como contrapoder e intertextualidad. La identidad se produce por la resistencia basada en la diferenciación y la conflictividad. ¿Qué es la identidad?. El cúmulo de conflictos y diferencias que tenemos. Es fundamental entender que la identidad no se genera en la mismidad, sino en la relación de lo mismo y lo otro. Vivimos en sociedades multiculturales, que "es y seguirá siendo una sociedad conflictiva" (COHNBENDIT y SCHMID, 1995:23).

En definitiva, la identidad se sustenta en el conflicto que genera lo no-similar. Y las actuales formas de construir el sistema de relaciones se basan en la homogeneización y la uniformización de nuestro complejo universo. He aquí el 
centro de la discusión. La identidad, pues, tiene relación con las creencias, las ideologías, los valores, los estereotipos, los prejuicios, los códigos, las semantizaciones, los sentidos, los referentes, la historia (el pasado), las reivindicaciones (aquello que inicialmente fue de un grupo) y las demandas (aquello que dicho grupo considera haber perdido debido al contexto desventajoso en que se encuentra). Vivimos en sociedades de inmigración (entre países, regiones, etc.) y el "problema no es la inmigración en si, sino las imágenes que circulan sobre ella" (COHN-BENDIT y SCHMID, 1995:60).

\section{Bibliografía}

AYLWIN, J. (1999). Pueblos indígenas de Chile: antecedentes históricos y situación actual. Temuco: Instituto de Estudios Indígenas-Universidad de La Frontera.

BARTH, F. (1976). Los grupos étnicos y sus fronteras. La organización social de las diferencias culturales. México D.F.: FCE.

BECK, U. (1998). ¿Qué es la globalización?. Falacias del globalismo, respuestas a la globalización. Barcelona: Paidós.

BENGOA, J . (1987). Historia del pueblo mapuche. Santiago de Chile: Sur Ediciones.

BODEI, R. (2000). "Los sin patria", en SILVEIRA, Héctor (Ed.): Identidades comunitarias y democracia. Madrid: Trotta.

CARDONA, G. (1994). Los lenguajes del saber. Barcelona: Gedisa.

CARRASCO, H. (2002). "El discurso público mapuche: noción, tipos discursivos e hibridez", en Estudios Filológicos, no 37. Valdivia: Universidad Austral de Chile.

CARRASCO, H. (2001). "Rasgos identitarios del discurso público mapuche", en Universum. Talca: Universidad de Talca. 


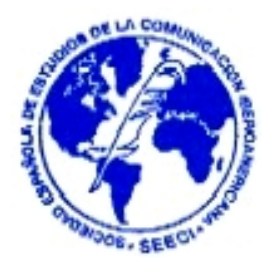

DAVINSON, G. (2000). Reforma al sistema judicial chileno: implicancias para el pueblo mapuche. Temuco: Instituto de Estudios Indígenas-Universidad de La Frontera.

DEL VALLE, Carlos (2004). Metainvestigación de la comunicación en Chile (1970-2004). Ediciones Universidad de La Frontera, Temuco. En Prensa.

DEL VALLE, Carlos (2004). Comunicación intercultural. Genealogía, crítica y perspectivas. Instituto Europeo de Comunicación y Desarrollo, Sevilla. En prensa.

DEL VALLE, Carlos (2003a). Comunicar la salud. Entre la equidad y la diferencia. Ediciones Universidad de La Frontera, Temuco, Chile. ISBN 956-236-144-6.

DEL VALLE, Carlos (2003b). "La identidad en un doble juego: resistencia y apertura...o el aprendizaje del cinismo. La construcción social del llamado "conflicto mapuche" en Chile, en publicaciones electrónicas realizadas por los propios mapuches". En Diálogos de la comunicación, № 66, Federación Latinoamericana de Facultades de Comunicación Social, FELAFACS, Lima. Pp. 90-97.

DEL VALLE, Carlos (2003c). "Interculturalidad y justicia. De la violencia de la escritura a la economía procedimental de la oralidad". En Ambitos. Revista Andaluza de Comunicación, Universidad de Sevilla, España. №s 9 y 10, Sevilla. Pp. 87-101.

DEL VALLE, Carlos (2003d). "Hacia una pedagogía de la comunicación intercultural: bases desde la producción oral, radial y mediática". En Comuniquiatras, Revista Internacional, Doctorado Interdisciplinar en Estudios Culturales: Literatura y Comunicación, del Departamento de Comunicación Audiovisual, Publicidad y Literatura de la Facultad de Comunicación de la Universidad de Sevilla, España.

DEL VALLE, Carlos (2003e). "La construcción social del llamado 'conflicto mapuche' en Chile, en publicaciones periódicas electrónicas realizadas por los propios mapuches...", en revista electrónica Orígenes, Ministerio de Educación /Ministerio de Planificación, Chile. 


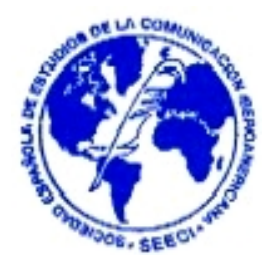

DEL VALLE, Carlos (2002a). "La estructura argumentativa de un tipo particular de discurso jurídico. El caso de cuatro demandas de reivindicación territorial mapuche (IX Región - Chile)". En Revista de la Facultad, Facultad de Derecho y Ciencias Sociales, Universidad Nacional del Comahue/PubliFadecs, Argentina. Año 7, № 7. Pp. 41-50.

DEL VALLE, Carlos (2002b). "La estructura argumentativa de un tipo particular de discurso jurídico. El caso de cuatro demandas de reivindicación territorial mapuche (IX Región - Chile) y sus implicancias identitarias". En Ambitos. Revista Andaluza de Comunicación, Universidad de Sevilla, España. Nos 7 y 8. Pp. 181-196.

DEL VALLE, Carlos (2002c). "Los desafíos interculturales de la justicia en Chile: De la violencia y el racismo del lenguaje a la tecnologización y economía del lenguaje y los procedimientos". En revista electrónica Orígenes, del Ministerio de Educación y del Ministerio de Planificación, Chile.

DEL VALLE, Carlos (2002d). "El proceso judicial de 12 mapuches en Chile: entre el racismo de Estado y la violencia del lenguaje". En Razón y Palabra, Primera Revista Electrónica en América Latina Especializada en Tópicos de Comunicación, № 26.

DEL VALLE, Carlos (2001a). "El uso de descripciones factuales como estrategias comunicativas de legitimación discursiva: el recurso de Ley de Seguridad del estado en el proceso judicial de 12 mapuches en la IX Región (Dic. 1997-Abril 1999)". En Estudios Criminológicos y Penitenciarios, Gendarmería de Chile y Ministerio de Justicia de Chile. № 3, pp. 117-130.

DEL VALLE, Carlos (2001b). "La estructura argumentativa de un tipo particular de discurso jurídico. El caso de cuatro demandas de reivindicación territorial mapuche (IX Región - Chile) y sus implicancias identitarias". En Estudios Criminológicos y Penitenciarios, Gendarmería de Chile y Ministerio de Justicia de Chile. № 2, pp. 25-40. 


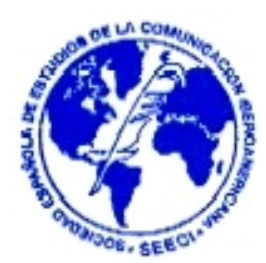

DEL VALLE, Carlos (2000a). "La estructura argumentativa de un tipo particular de discurso jurídico". En Lengua y Literatura Mapuche, Universidad de La Frontera, Chile. № 9, pp. 169-176.

DEL VALLE, Carlos (2000b). "La producción de comunicación (medial) en contextos educativos interculturales". En Educación y Humanidades, Universidad de La Frontera, Chile. № 9, pp. 27-37.

DEL VALLE, Carlos (1998). "Reconstrucción de la historia en el discurso jurídico mapuche, a propósito de una demanda de reivindicación territorial". En Lengua y Literatura Mapuche, Universidad de La Frontera, Chile. № 8, pp. 233-242.

DERRIDA, J. (1971). De la gramatología. Buenos Aires: Siglo XXI.

DERRIDA, J. (1988). Márgenes de la filosofía. Madrid: Cátedra.

DERRIDA, J. (1989). La escritura y la diferencia. Barcelona: Anthropos.

FOUCAULT, M. (1992). Genealogía del racismo. Madrid: La Piqueta.

FOUCAULT, M. (1992). Vigilar y castigar. Madrid: La Piqueta.

FOUCAULT, M. (1995). La verdad y las formas jurídicas. Barcelona: Gedisa.

GARCÍA- CANCLINI, N. (1989). Culturas híbridas. Estrategias para entrar y salir de la modernidad. México D.F.: Grijalbo.

GRIMSON, A. (2000). Interculturalidad y comunicación. Buenos Aires: Norma.

LACLAU, E. (2000). "Universalismo, particularismo y el tema de la identidad", en SILVEIRO, Héctor (Ed): Identidades comunitarias y democracia. Madrid: Trotta.

LÉVI-STRAUSS, C. (1964). El pensamiento salvaje. México D.F.: FCE. 


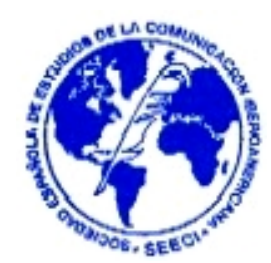

MARIACA, G. (1999). Los refugios de la utopía. Apuntes teóricos para una política Inter-cultural. Bolivia: Sierpe.

MARCONE, J. (1997). La oralidad escrita. Sobre la reivindicación y re-inscripción del discurso oral. Perú: Fondo Editorial.

MORENO, I. (1996). "Etnicidades, estados, migraciones y violencia: el carácter obsoleto del modelo de Estado-nación", en Diversidad étnica y conflicto en América Latina. México D.F.: Plaza y Valdés.

MORENO, I. (2002). "Religión, estado y mercado. Los sacros de nuestro tiempo", en ZAMBRANO, C. (Ed): Confesionalidad Política. Confrontaciones multiculturales por el monopolio religioso, pp. 35-52. Bogotá: Universidad Nacional de Colombia.

OLIVÉ, L. (1999). Multiculturalismo y pluralismo. Madrid: Paidós.

ONG, W. (1987). Oralidad y escritura. Tecnologías de la palabra. México: Fondo de Cultura Económica.

PAINEQUEO, H. (1994). El discurso en castellano de un hablante nativo del mapudungün, en Lengua y Literatura Mapuche, № 6. Temuco: Universidad de La Frontera.

POTTER, J. (1998). La representación de la realidad. Barcelona: Gedisa.

SILVEIRA, H. (2000). Identidades comunitarias y democracia. Madrid: Trotta.

TIERNEY, P.; AILLAPÁN, L. (1998). El Altar más Alto. New York: Viking Press. 